Original article

\title{
Specificities of small airways dysfunction development in patients with mild asthma
}

\author{
Elena E. Mineeva, Marina V. Antonyuk, Alla V. Yurenko, Tatyana A. Gvozdenko, Oksana Yu. Kytikova
}

Vladivostok Branch of Far Eastern Scientific Centre of Physiology and Pathology of Respiration - Institute of Medical Climatology and Rehabilitative Treatment, Vladivostok, Russia

Received 25 May 2020, Revised 8 October 2020, Accepted 17 February 2021

(C) 2020, Mineeva E.E., Antonyuk M.V., Yurenko A.V., Gvozdenko T.A., Kytikova O.Yu.

(C) 2020, Russian Open Medical Journal

Abstract: The study goal was to identify specificities of small airways dysfunction development (SAD) in patients with mild asthma.

Material and Methods - The study involved 114 patients with mild asthma. Depending on the condition of their small airways, the patients were split among two groups: Group 1 of 94 patients with asthma without SAD (82.5\%); Group 2 of 20 patients with asthma and SAD (17.5\%). The control group consisted of 25 volunteers. SAD was diagnosed by the presence of air trapping and hyperinflation.

Results - SAD was diagnosed in $17.5 \%$ of patients with mild asthma. The development of SAD was observed in $80 \%$ of asthma patients with ailment duration of over 5 years and family history of asthma. Obesity was diagnosed 1.7 times more often in patients with SAD compared with those without it. Food allergy, allergic rhinitis, allergic conjunctivitis, urticaria and bronchial obstruction were identified two or more times more often in patients with SAD compared with those without it. Among all patients with mild asthma and SAD, bronchial obstruction was detected in $55 \%$ of cases.

Conclusion - The development of SAD in the presence of mild asthma is characteristic for patients with ailment duration over 5 years, family history of asthma, obesity, predominant sensitization to food allergens, and concomitant non-pulmonary allergic diseases. Bronchial obstruction is not the obligatory feature of SAD development in presence of mild asthma.

Keywords: mild asthma, small airways dysfunction.

Cite as Mineeva EE, Antonyuk MV, Yurenko AV, Gvozdenko TA, Kytikova OYu. Specificities of small airways dysfunction development in patients with mild asthma. Russian Open Medical Journal 2021; 10: e0105.

Correspondence to Elena E. Mineeva. Address: 73-g Russkaya St., Vladivostok 690105, Russia. Phone: +79147362721. E-mail: elmineeva@yandex.ru.

\section{Introduction}

Currently, asthma remains among global public health concerns. It has been reported that uncontrolled asthma accounted of over $50 \%$ of all asthma cases [1]. Mild asthma is diagnosed in approximately $50-70 \%$ of asthmatic patients. Despite the fact that mild asthma is not the matter for significant concern on behalf of a clinician and a patient, cases of severe asthma exacerbation and even status asthmaticus are often detected [2].

Traditionally, asthma has been viewed as a disease of large and medium bronchi, but there is currently convincing evidence of a contribution of the small airways to asthma pathogenesis [3, 4]. It is known that, in addition to central bronchi, the small airways (i.e., the bronchi with an inner diameter of under $2 \mathrm{~mm}$ ), are also involved in asthma [5].

The vast majority of patients with severe asthma exhibit small airways dysfunction (SAD), which is currently considered a pathogenetic component of the disease $[6,7]$. The presence of SAD can predetermine the uncontrolled course of asthma, which makes it an important target for therapy [8]. The role of the small airway in asthma pathophysiology is a subject of ongoing clarification. It remains unknown whether all asthma patients have SAD or there is, so to speak, an asthma phenotype with SAD [9].
Most studies demonstrating changes in the peripheral airways have been performed in the presence of severe asthma. An assessment of the small airway condition at early stages of this ailment is of great importance for the patients with normal values of basic pulmonary function tests and without pronounced clinical symptoms. The factors determining the development of SAD in patients with mild asthma remain unclear.

The goal of our study was to identify specificities of SAD development in patients with mild asthma.

\section{Material and Methods \\ Study design}

The design of our research was a single-center prospective comparative study. The study involved 114 subjects with partly controlled mild asthma who were examined and treated at the Clinical Division of Research Institute of Medical Climatology and Rehabilitation Therapy (Vladivostok, Russian Federation) over the period of 2018-2019. The control group consisted of 25 volunteers without bronchopulmonary pathology.

Asthma was diagnosed sensu the classification and the criteria of the international consensus on asthma diagnosing and treatment (GINA) [10]. The criteria for partly controlled asthma were the presence of one or two of the following symptoms over 
the past four weeks: daytime asthma manifestations more than twice a week; nighttime awakening caused by asthma; taking short-acting $\beta 2$-agonists (bronchodilators) more than twice a week; any restrictions of activity due to asthma. The ACQ-5 test (Asthma Control Questionnaire) was used to determine the level asthma management; the scores ranged 0.75-1.5, which implied the presence of partly controlled asthma [10].

The inclusion criteria for the study involved non-smoking patients with partly controlled mild asthma. The exclusion criteria encompassed smoking patients with asthma, uncontrolled asthma, chronic obstructive pulmonary disease, occupational diseases of bronchopulmonary system, and disorders of internal organs at the stage of decompensation.

All asthma patients received basic therapy with a fixed combination of a low-dose inhaled glucocorticoid (budesonide: 200-400 $\mu \mathrm{g} /$ day) and a long-acting $\beta 2$-agonist (formoterol) (steps 1 and 2 of GINA-2019). The study was conducted in accordance with the Declaration of Helsinki (2013) and was approved by the Ethics Committee at the Institute of Medical Climatology and Rehabilitation Therapy. All participants have signed a written informed consent.

The following single-visit procedures were performed in patients with asthma: physical examination by a pulmonologist, filling out an ACQ-5 questionnaire, spirometry, and body plethysmography. Pulmonary function analysis was performed in accordance with the requirements of the European Respiratory Society (ERS) and the American Thoracic Society (ATS). The pulmonary function analysis after salbutamol $(400 \mu \mathrm{g})$ inhalation was carried out to assess the reversibility of airway obstruction.

\section{Analysis of pulmonary function}

Pulmonary function testing was conducted on MasterScreen Body equipment (Germany). Vital capacity (VC), inspiratory capacity (IC), forced vital capacity (FVC), forced expiratory volume in 1 second $\left(F E V_{1}\right)$, the ratio of $F E V_{1}$ and $V C\left(F E V_{1} / \mathrm{VC}\right)$, the ratio of $\mathrm{FEV}_{1}$ and $\mathrm{FVC}\left(\mathrm{FEV}_{1} / \mathrm{FVC}\right)$, maximal expiratory flow at $25 \%$ of $\mathrm{FVC}$ $\left(\mathrm{MEF}_{75}\right)$, maximal expiratory flow at $50 \%$ of $\mathrm{FVC}\left(\mathrm{MEF}_{50}\right)$, maximal expiratory flow at $75 \%$ of FVC $\left(\mathrm{MEF}_{25}\right)$, and maximal midexpiratory flow $\left(\mathrm{MMEF}_{25-75}\right)$ were monitored by spirometry. The static lung volumes and capacities, such as functional residual capacity measured by plethysmography (FRCplet), residual volume $(R V)$, total lung capacity (TLC), the ratio of RV and TLC (RV/TLC), inhalation resistance $\left(R_{\text {in }}\right)$ and exhalation resistance $\left(R_{\text {ex }}\right)$ were measured using body plethysmography.

When analyzing lung volumes, we used the predicted values calculated according to ATS/ERS recommendations (2005). The data are expressed as percentages of predicted values (obtained value/predicted value $\times 100 \%$ ) [11].

Small airways dysfunction was diagnosed by the presence of air trapping (an increase in RV and RV/TLC ratio above $140 \%$ and $125 \%$ of predicted values, respectively), as well as by the presence of hyperinflation (an increase in FRCplet above 120\% of predicted value) [12]

Table 1. Clinical characteristics of asthma patients vs. condition of small airways

\begin{tabular}{|c|c|c|c|}
\hline Parameters & $\begin{array}{c}\text { Control group, } \\
n=25\end{array}$ & $\begin{array}{l}\text { Asthma without small airway } \\
\text { dysfunction (group 1), } n=94\end{array}$ & $\begin{array}{l}\text { Asthma with small airway } \\
\text { dysfunction (group 2), } n=20\end{array}$ \\
\hline Age, years & $38.00 \pm 10.67$ & $41.81 \pm 13.57$ & $45.11 \pm 19.08$ \\
\hline \multicolumn{4}{|l|}{ Gender: } \\
\hline a) male & $14(56 \%)$ & 35 (37\%) & $9(45 \%)$ \\
\hline b) female & $11(44 \%)$ & $59(63 \%)$ & $11(55 \%)$ \\
\hline Body mass index $(\mathrm{BMI}), \mathrm{kg} / \mathrm{m}^{2}$ & $24.59 \pm 3.38$ & $27.54 \pm 5.96$ & $29.01 \pm 5.14$ \\
\hline \multicolumn{4}{|l|}{ Weight: } \\
\hline a) normal weight or overweight (BMI $18.5-29.9 \mathrm{~kg} / \mathrm{m}^{2}$ ) & $25(100 \%)$ & $64(68 \%)$ & $9(45 \%)$ \\
\hline b) class 1 obesity (BMI $30.0-34.99 \mathrm{~kg} / \mathrm{m}^{2}$ ) & & $30(32 \%)$ & $11(55 \%)$ \\
\hline \multicolumn{4}{|l|}{ Duration of asthma: } \\
\hline a) $1-5$ years & - & $52(55 \%)$ & $4(20 \%)$ \\
\hline b) $>5$ years & & $42(45 \%)$ & $16(80 \%)$ \\
\hline \multicolumn{4}{|l|}{ Family history of asthma: } \\
\hline a) no & - & $38(40 \%)$ & $4(20 \%)$ \\
\hline b) yes & & $56(60 \%)$ & $16(80 \%)$ \\
\hline \multicolumn{4}{|l|}{ Allergy: } \\
\hline a) household & & $60(64 \%)$ & $15(75 \%)$ \\
\hline b) pollen & & $48(51 \%)$ & $15(75 \%)$ \\
\hline c) food & - & $18(19 \%)$ & $7(35 \%)$ \\
\hline d) drug & & $15(16 \%)$ & $3(15 \%)$ \\
\hline e) fungal & & $2(2 \%)$ & - \\
\hline \multicolumn{4}{|l|}{ Non-pulmonary allergic diseases: } \\
\hline a) allergic rhinitis & & $33(35 \%)$ & $14(70 \%)$ \\
\hline b) allergic conjunctivitis & - & $7(7 \%)$ & $3(15 \%)$ \\
\hline c) urticaria & & $8(9 \%)$ & $5(25 \%)$ \\
\hline \multicolumn{4}{|l|}{ Bronchial obstruction: } \\
\hline a) no & - & $75(80 \%)$ & $9(45 \%)$ \\
\hline b) yes & & $19(20 \%)$ & $11(55 \%)$ \\
\hline ACQ-5, scores & - & $1.2(0.8,1.4)$ & $1.4(1.1,1.5)$ \\
\hline
\end{tabular}

Data are presented as a mean and standard deviation (normal distribution), or a median with lower and upper quartiles (distributions other than normal); $\chi^{2}$ expected $>\chi^{2}$ critical; $\chi^{2}$ expected $=99.004, \chi^{2}$ critical $=76.201 ; p<0,001$. 
Table 2. Pulmonary function parameters of asthma patients vs. condition of small airways

\begin{tabular}{|c|c|c|c|}
\hline $\begin{array}{l}\text { Pulmonary } \\
\text { parameters }\end{array}$ & Control group, $n=25$ & $\begin{array}{l}\text { Asthma without small airway } \\
\text { dysfunction (group 1), } n=94\end{array}$ & $\begin{array}{l}\text { Asthma with small airway dysfunction } \\
\text { (group 2), } n=20\end{array}$ \\
\hline VC, $\%$ of predicted & $108.41(98.05,119.71)$ & $110.95(102.23,120.91)$ & $93.69(82.28,102.41)\left(p<0.001, p_{1}<0.001\right)$ \\
\hline IC, $\%$ of predicted & $108.92(93.05,120.05)$ & $113.20(100.63,130.63)$ & $95.32(88.21,107.95)\left(p_{1}=0.005\right)$ \\
\hline FVC, $\%$ of predicted & $107.41(99.65,119.52)$ & $110.71(103.01,120.05)$ & $93.35(80.58 ; 99.21)\left(p<0.001, p_{1}<0.001\right)$ \\
\hline $\mathrm{FEV}_{1}, \%$ of predicted & $104.91(95.05,111.25)$ & $98.95(91.12,110.81)$ & $75.55(65.28,82.81)\left(p<0.001, p_{1}<0.001\right)$ \\
\hline $\mathrm{FEV}_{1} / \mathrm{VC}, \%$ & $75.98(72.81,83.27)$ & $79.03(71.96,88.78)$ & $67.89(56.97,76.01)\left(p=0.002, p_{1}<0.001\right)$ \\
\hline $\mathrm{FEV}_{1} / \mathrm{FVC}, \%$ & $79.39(74.85,84.75)$ & $76.87(72.04,80.45)(p=0.012)$ & $66.69(61.63,74.83)\left(p=0.001, p_{1}=0.023\right)$ \\
\hline $\mathrm{MEF}_{75}, \%$ of predicted & $96.21(87.21,108.31)$ & $89.51(72.05,110.03)(p=0.041)$ & $47.15(30.23,66.23)\left(p<0.001, p_{1}<0.001\right)$ \\
\hline $\mathrm{MEF}_{50}, \%$ of predicted & $83.52(66.71,108.25)$ & $66.92(50.43,84.65)(p=0.001)$ & $31.55(23.65,58.28)\left(p<0.001, p_{1}<0.001\right)$ \\
\hline $\mathrm{MEF}_{25}, \%$ of predicted & $50.71(41.61,79.15)$ & $45.12(33.73,64.25)(p=0.042)$ & $27.32(16.38,61.83)\left(p=0.012, p_{1}=0.041\right)$ \\
\hline $\mathrm{MMEF}_{25-75}, \%$ of predicted & $75.91(58.95,92.85)$ & $61.13(45.71,76.25)(p=0.007)$ & $26.15(19.83,56.32)\left(p<0.001, p_{1}=0.002\right)$ \\
\hline $\mathrm{R}_{\mathrm{in}}, \mathrm{kPa} *_{\mathrm{s}} / \mathrm{l}$ & $0.17(0.13,0.21)$ & $0.20(0.14,0.27)$ & $0.30(0.18,0.51)\left(p=0.005, p_{1}=0.042\right)$ \\
\hline $\mathrm{R}_{\mathrm{ex}}, \mathrm{kPa} * \mathrm{~s} / \mathrm{l}$ & $0.23(0.15,0.29)$ & $0.28(0.21,0.35)$ & $0.44(0.21,0.98)\left(p=0.005, p_{1}=0.034\right)$ \\
\hline $\mathrm{FRC}_{\text {plet }}, \%$ of predicted & $106.90(93.85,120.65)$ & $99.65(88.33,114.78)$ & $129.42(106.83,146.3)\left(p<0.001, p_{1}<0.001\right)$ \\
\hline RV, $\%$ of predicted & $98.01(85.20,114.11)$ & $99.95(89.85,112.51)$ & $150.31(142.28,175.58)\left(p<0.001, p_{1}<0.001\right)$ \\
\hline TLC, $\%$ of predicted & $98.02(92.25,110.10)$ & $104.51(96.03,111.32)$ & $109.05(100.38,115.25)(p=0.032)$ \\
\hline RV/TLC, \% & $91.82(87.42,100.01)$ & $97.12(81.75,107.53)$ & $39.25(131.18,147.35)\left(p<0.001, p_{1}<0.001\right)$ \\
\hline
\end{tabular}

Data are presented as medians with lower and upper quartiles (non-normal distributions); $\mathrm{p}$ - statistical significance of differences between the asthma groups and the control group; $p_{1}$ - statistical significance of differences between Group 1 and Group 2 .

\section{Statistical analysis}

Statistical analysis was performed using the Statistica 6.1 software for Windows. For assessing normality of distributions of quantitative variables in groups, we employed KolmogorovSmirnov, Shapiro-Wilk and Pearson's chi-square $\left(\chi^{2}\right)$ tests. Descriptive statistics are presented as means and standard deviations (for normally distributed variables), or medians with lower and upper quartiles (non-normal distributions). Statistical differences between parameters were tested using the Student's t-test (for normal distribution), or else Mann-Whitney and Kolmogorov-Smirnov criteria (for distributions other than normal). A $p$-value $<0.05$ was considered statistically significant.

\section{Results}

Depending on the functional state of small airways (Table 1), the asthma patients were split among two groups: Group 1 included 94 asthma patients without SAD (82.5\%) and Group 2 contained 20 asthma patients with SAD (17.5\%).

The clinical characteristics of asthma patients are presented in Table 1. The significance of differences between the groups of patients with mild asthma with and without SAD was assessed using the $\chi^{2}$ test. When comparing the observed chi-square value with the critical chi-square value $(99.004>76.201)$, statistically significant differences in the frequencies of studied parameters between Group 1 and Group 2 were established $(p<0.001)$. The development of SAD was mainly observed in subjects with mild asthma (Group 2) with disease duration of over 5 years $(80 \%$ of cases) and asthma patients with a family history of asthma (80\% of cases). Obese patients accounted for $55 \%$ of asthma patients in Group 2 and just 32\% of asthma patients in Group 1. Most asthmatic patients in groups 1 and 2 had a sensitization to household ( $64 \%$ and $75 \%$ of cases, respectively) and pollen (51\% and $75 \%$ of cases, correspondingly) allergens. The patients with SAD exhibited food allergy almost twice as frequently as patients without SAD. Non-pulmonary allergic diseases, such as allergic rhinitis, allergic conjunctivitis, and urticaria were diagnosed in the patients with SAD at more than twice the rate of the patients without it.
In this study, bronchial obstruction was detected in $55 \%$ of patients with mild asthma and SAD (Group 2), while patients with mild asthma but without SAD (Group 1) were 2.7 times (20\%) less likely to have this diagnosis. It should be emphasized that $45 \%$ of patients in Group 2 and 80\% of patients in Group 1 did not have any signs of bronchial obstruction.

It should be highlighted that the pulmonary function parameters, assessed by spirometry and body plethysmography in Group 1, were within the range of predicted values (Table 2). Yet, compared with the control group, bronchial patency parameters were significantly reduced, including $\mathrm{FEV}_{1} / \mathrm{FVC}$ by $3.2 \%(p=0.012)$, $\mathrm{MEF}_{75}$ by $7.0 \%(\mathrm{p}=0.041) ; \mathrm{MEF}_{50}, \mathrm{MEF}_{25}$ and $\mathrm{MMEF}_{25-75}$ by $19.9 \%$ $(p=0.001), 11.0 \%(p=0.042)$, and $19.5 \%(p=0.007)$, respectively.

According to spirometry, the asthma patients with SAD (Group 2) displayed mild obstruction, characterized by decrease in $\mathrm{FEV}_{1}$, $\mathrm{FEV}_{1} / \mathrm{VC}$ and $\mathrm{FEV}_{1} / \mathrm{FVC}(75.55 \%, 67.89 \%$ and $66.69 \%$ of their predicted values, correspondingly). As expected, the abovementioned parameters of pulmonary function in these patients were significantly decreased by $28 \%(p<0.001), 10.6 \% \quad(p=0.002)$ and $16 \%(p=0.001)$ relative to the control group. The maximal expiratory flow parameters, such as $\mathrm{MEF}_{75}, \mathrm{MEF}_{50}, \mathrm{MEF}_{25}$ and $\mathrm{MMEF}_{25-75}$, in these groups were $2(\mathrm{p}<0.001), 2.6(\mathrm{p}<0.001), 1.8$ $(p=0.01)$ and $2.9(p<0.001)$ times lower, respectively, than the control values. Airway resistance in the asthma patients with $S A D$ was amplified by 1.8 times $(p=0.005)$ during inspiration and by 1.9 times $(p=0.005)$ during expiration, compared with the control group. The established changes in the pulmonary function parameters in Group 2 have indicated mild generalized bronchial obstruction.

A comparative analysis of the pulmonary function parameters in mild asthma patients with different conditions of small airways (Group 1 and Group 2) has shown a significant decline in all spirometric parameters in the patients with SAD. The patients in the Group 2 versus Group 1 had reduced values of FVC (by $15.7 \%$, $\mathrm{p}<0.001$ ), $\mathrm{FEV}_{1}$ (by $23.7 \%, \mathrm{p}<0.001$ ), $\mathrm{FEV}_{1} / \mathrm{VC}$ (by $14.1 \%, \mathrm{p}<0.001$ ), and $\mathrm{FEV}_{1} / \mathrm{FVC}$ (by $13.2 \%, \mathrm{p}=0.023$ ). The maximal expiratory flow parameters, specifically $\mathrm{MEF}_{75}, \mathrm{MEF}_{50}, \mathrm{MEF}_{25}$ and $\mathrm{MMEF}_{25-75}$, were also significantly decreased by 1.9 times $(p<0.001), 2.1$ times $(p<0.001), 1.6$ times $(p=0.041)$ and 2.3 times $(p=0.002)$, correspondingly. According to body plethysmography, airway 
resistance in Group 2 was enlarged 1.5 times $(p=0.042)$ during inspiration and 1.6 times $(p=0.034)$ in the course of expiration, which was typical for proximal bronchial obstruction. Therefore, patients with SAD had impaired pulmonary function of both central and peripheral parts of the tracheobronchial tree.

\section{Discussion}

In our study, signs of SAD, specifically, air trapping (RV and RV/TLC over $140 \%$ and $125 \%$ of predicted values, respectively) and hyperinflation (FRCplet over $120 \%$ of predicted level) were identified in $17.5 \%$ of patients with mild asthma. According to available published data, the prevalence of SAD detected by body plethysmography among adults with asthma is 20-64\% [5]. Peripheral airways are difficult to access. In this regard, there are no multipurpose methods of peripheral airways and distal lungs evaluation in the presence of asthma $[3,8]$.

Published data on the development of SAD in mild asthma is lacking. In our study, we have established that SAD development was observed mainly in patients with mild asthma (Group 2) with presence of a family history of asthma and ailment duration of over five years (Table 1). Obesity and food allergy were more common in patients with SAD (1.7 and 1.8 times, correspondingly, versus patients without SAD). Non-pulmonary allergic diseases, such as allergic rhinitis, allergic conjunctivitis and urticaria, were diagnosed two or more times more often in patients with SAD versus patients without it.

We discovered that SAD in patients with mild asthma (Group 2) was accompanied by bronchial obstruction in $55 \%$ of cases, which exceeded the same parameter in Group 1 by 2.7 times (Table 1). In this study, SAD in mild asthma was diagnosed not only in the patients with bronchial obstruction, but also in those with normal values of pulmonary function parameters. Our finding of SAD in $45 \%$ of patients with mild asthma but no signs of impaired bronchial patency implied the need for timely $S A D$ diagnosis in order to develop the personalized treatment strategy. The established frequency of impaired bronchial patency in patients with SAD indicated that bronchial obstruction in mild asthma was not an obligatory feature of SAD development. It is also worth pointing out that the phenotype of bronchial asthma with SAD includes the patients with asthma, SAD, normal FEV1 values and uncontrolled course of the disease [13].

The presence of SAD, confirmed by body plethysmography and reduction in a mean value of FEV 1 to $75.55 \%$ of its predicted value, identified by spirometry (Table 2 ) in patients of Group 2, indicated a mild distal obstruction. Airway resistance, assessed by body plethysmography, was moderately augmented during expiration, which was characteristic of a proximal obstruction. Our data provided evidence of mild generalized bronchial obstruction development in patients with mild asthma and SAD. According to available publications, distal airways dysfunction in asthma patients was not always associated with bronchial obstruction because contribution of small airways to the total airflow resistance did not conventionally exceed $10 \%$. The contribution of small airways to amplified resistance was greatly enhanced by the airway lumina narrowing [14].

Statistically significant decline in FVC and $\mathrm{MMEF}_{25-75}$ values, detected in patients of Group 2, compared with the Group 1, is an indirect evidence for the presence of SAD (Table 2). FVC reduction is presumably an indicator of air trapping $[14,15]$. It has been discovered that pulmonary function impairment in severe asthma patients was caused by the air traps, measured indirectly by FVC reduction, and their severity prevailed over the severity of bronchial obstruction, determined by $\mathrm{FEV}_{1} / \mathrm{FVC}$. However, significant air trapping has not been detected in non-severe asthma - even in the presence of a significant bronchial obstruction [5, 19].

As reported by Marseglia G.L. et al., spirometric parameter $\mathrm{MMEF}_{25-75}$ is most often considered an indicator of small airways obstruction [16]. Nevertheless, changes in $\mathrm{MMEF}_{25-75}$ are variable and depend on the severity of central airway obstruction and lung volume [17]. Another study demonstrated no correlation between the inflammation of small airways and $\mathrm{MMEF}_{25-75}$ [17]. The established $\mathrm{MMEF}_{25-75}$ reduction in our study, against the background of a mild obstruction, favors the explanation that this parameter may be one of the indicators of small airways obstruction. The findings of Yuan $\mathrm{H}$. et al. suggested the possibility of using $M M^{25-75}$ as a marker of early SAD in patients with a cough-variant asthma with a normal FEV1 [18].

Among all flow-volume parameters in patients with asthma, $\mathrm{RV}$ is the most sensitive; it often deviates from the norm and is the last to return to a normal level in response to adequate therapy [20]. Increased RV is an indirect indicator of air trapping [20,21]. According to the published results, TLC is also elevated in asthma, but it can be within its normal range of values at the initial stages of the disease. Due to typically increased TLC in patients with obstructive disorders and large variability of RV, the RV/TLC ratio may be more useful for assessing an increase in $\mathrm{RV}[19,22]$. In our study, statistically significant reduction in VC and IC, detected by spirometry, was characteristic for asthma patients with SAD versus those without it (Table 2). These parameters are conventionally used to calculate the total lung capacity $(T L C=V C+R V$ and $T L C=I C+F R C p l e t)$. Consequently, if TLC values are normal, a decline of VC (identified from spirometric data) indirectly indicates an enlargement of RV and formation of air traps, whereas a decrease in IC reflects an upsurge in FRCplet and development of pulmonary hyperinflation. We observed normal values of TLC in all subjects, but it was statistically significantly higher in Group 2 than in the control group (Table 2). Thus, the results of our study have confirmed that IC values allowed for indirect estimates of intrathoracic volume or FRCplet, which complied with the literature data [10]. The IC values decline with the development of a lung hyperinflation, while TLC remains within its normal range or increases.

Hence, SAD in patients with mild asthma was diagnosed in normal pulmonary function rather than in generalized bronchial obstruction alone. The mechanism of SAD development in the presence of mild asthma requires further research.

\section{Conclusion}

Small airways dysfunction (SAD) in patients with partly controlled mild asthma was detected in $17.5 \%$ of cases. Among patients with a mild asthma, SAD prevails in those with a family history of asthma, and also with obesity, concomitant allergic diseases (allergic rhinitis, allergic conjunctivitis, urticaria), and predominant sensitization to food allergens. The development of SAD in patients with mild asthma does not depend on the presence or absence of bronchial obstruction. Timely diagnosis of SAD in patients with mild asthma and the use of extra-fine inhalation agents reaching the distal airways would make it possible to achieve better disease control. 


\section{Ethical approval}

The study was conducted in compliance with the Declaration of Helsinki (2013), and the protocol was approved by the Ethics Committee of the Research Institute of Medical Climatology and Rehabilitation Therapy, Vladivostok Branch of Far Eastern Scientific Center for Physiology and Pathology of Respiration.

\section{Conflict of interest: We declare no conflict of interest.}

\section{References}

1. Sinopalnikov AI, Belotserkovskaya YuG, Romanovsky AG. Potentials for the optimizing the control of bronchial asthma: small airways and extra-fine-dispersed forms of inhalers. Farmateka 2018; (8): 49-57. Russian. https://doi.org/10.18565/pharmateca.2018.8.49-57.

2. Avdeev SN, Aisanov ZR, Belevsky AS, Kulbaisov AM, Kurbacheva OM, Leshchenko IV, et al. Mild bronchial asthma: the present and the future. Pulmonologiya 2018; 28(1): 84-95. Russian. https://doi.org/10.18093/0869-0189-2018-28-1-84-95.

3. Moiseev SV. Lesion of small airways in bronchial asthma. Klinicheskaja farmakologija I terapija 2012; 21(5): 5-10. Russian https://elibrary.ru/item.asp?id=22577316.

4. Nenasheva NM. Role of small airways in bronchial asthma. Atmosfera. Pul'monologija i allergologija 2010; (4): 27-33. Russian. https://elibrary.ru/item.asp?id=15582359.

5. Nenasheva NM. Contemporary understanding of bronchial asthma phenotypes. Farmateka 2013; 4: 41-46. Russian. https://elibrary.ru/item.asp?id=19001770.

6. Usmani OS, Singh D, Spinola M, Bizzi A, Barnes PJ. The prevalence of small airways disease in adult asthma: A systematic literature review. Respir Med 2016; 116: 19-27. https://doi.org/10.1016/i.rmed.2016.05.006.

7. Fassakhov RS. Significant role of small respiratory tracts: new possibilities of cyclesonide in therapy of bronchial asthma. Meditsinskiy sovet 2017; (18): 56-60. Russian. https://doi.org/10.21518/2079-701x-2017-18-56-60

8. Singhania A, Rupani H, Jayasekera N, Lumb S, Hales P, Gozzard N, et al. Altered Epithelial Gene Expression in Peripheral Airways of Severe Asthma. PLoS One 2017; 12(1): e0168680. https://doi.org/10.1371/journal.pone.0168680.

9. Konstantinos Katsoulis K, Kostikas K, Kontakiotis T. Techniques for assessing small airways function: Possible applications in asthma and COPD. Respir Med 2016; 119: e2-e9. https://doi.org/10.1016/j.rmed.2013.05.003.

10. Savushkina OI, Chernyak AV. Theoretical and methodological aspects of body plethysmography and clinical applications. Bulletin physiology and pathology of respiration 2016; (60): 117-124. Russian. https://doi.org/10.12737/20131.

11. Global Initiative for Asthma: Global Strategy for Asthma Management and Prevention. 2019. https://ginasthma.org/wpcontent/uploads/2019/06/GINA-2019-main-report-June-2019wms.pdf.

12. Pellegrino R, Viegi G, Brusasco V, Crapo RO, Burgos F, Casaburi R, et al. Interpretative strategies for lung function tests. Eur Respir J 2005; 26(5): 948-968. https://doi.org/10.1183/09031936.05.00035205.

13. Lipworth B, Manoharan A, Anderson W Unlocking the quiet zone: The small airway asthma phenotype. Lancet Respir Med 2014; 2(6): 497506. https://doi.org/10.1016/S2213-2600(14)70103-1.

14. Avdeev SN, Aisanov ZR, Arkhipov VV, Belevsky AS, Geppe NA, Ilkovich $\mathrm{MM}$, et al. Coordinated rationale for the therapy choice for asthma and chronic obstructive pulmonary disease versus disease phenotype and small airways role. Atmosfera. Pul'monologija i allergologija 2013; (2): 15-26. Russian. https://elibrary.ru/item.asp?id=20307200.

15. Jarjour NN, Erzurum SC, Bleecker ER, Calhoun WJ, Castro M, Comhair $\mathrm{SA}$, et al. Severe asthma: Lessons learned from the National Heart,
Lung, and Blood Institute Severe Asthma Research Program. Am J Respir Crit Care Med 2012; 185(4): 356-362. https://doi.org/10.1164/rccm.201107-1317PP.

16. Marseglia GL, Cirillo I, Vizzaccaro A, Klersy C, Tosca MA, La Rosa M et al. Role of forced expiratory flow at $25-75 \%$ as an early marker of small airways impairment in subjects with allergic rhinitis. Allergy Asthma Proc 2007; 28: 74-78. https://doi.org/10.2500/aap.2007.28.2920.

17. Wagner EM, Bleecker ER, Permutt S, Liu MC. Direct assessment of small airways reactivity in human subjects. Am J Respir Crit Care Med 1998; 157(2): 447-452. https://doi.org/10.1164/ajrccm.157.2.9611043.

18. Yuan H, Li X, Li L, Wang G, Liu C, Zeng Y, et al. Clinical and pulmonary function changes in cough variant asthma with small airway disease. Allergy Asthma Clin Immunol 2019; 15: 41. https://doi.org/10.1186/s13223-019-0354-1.

19. Sorkness RL, Bleecker ER, Busse WW, Calhoun WJ, Castro M, Chung KF et al. Lung function in adults with stable but severe asthma: $\mathrm{Ar}$ trapping and incomplete reversal of obstruction with bronchodilation. J Appl Physiol (1985) 2008; 104(2): 394-403. https://doi.org/10.1152/japplphysiol.00329.2007.

20. Ueda $T$, Niimi A, Matsumoto $H$, Takemura $M$, Hirai $T$, Yamaguchi $M$, et al. Role of small airways in asthma: Investigation using high-resolution computed tomography. J Allergy Clin Immunol 2006; 118(5): 10191025. https://doi.org/10.1016/j.jaci.2006.07.032.

21. Mineeva EE, Antonyuk MV, Yurenko AV, Gvozdenko TA. Functional state of small airways in patients with bronchial asthma associated with obesity. Therapeutic Archive 2019; 91(1): 16-63. Russian. https://doi.org/10.26442/00403660.2019.01.000031.

22. Savushkina OI, Chernyak AV. Clinical application of body plethysmography. Atmosfera. Pul'monologija i allergologija 2013; (2): 38-41. Russian. https://elibrary.ru/item.asp?id=20307203.

\section{Authors:}

Elena E. Mineeva - MD, PhD, Research Scientist, Physician of Functional Diagnostics, Pulmonologist, Laboratory of Rehabilitation Therapy, Research Institute of Medical Climatology and Rehabilitation Therapy, Vladivostok Branch of Far Eastern Scientific Center for Physiology and Pathology of Respiration, Russian Academy of Medical Sciences, Vladivostok, Russia. https://orcid.org/0000-0002-4286-2827.

Marina V. Antonyuk - MD, DSc, Professor, Laboratory of Rehabilitation Therapy, Research Institute of Medical Climatology and Rehabilitation Therapy, Vladivostok Branch of Far Eastern Scientific Center for Physiology and Pathology of Respiration, Russian Academy of Medical Sciences, Vladivostok, Russia. https://orcid.org/0000-0002-2492-3198.

Alla V. Yurenko - MD, PhD, Laboratory of Rehabilitation Therapy, Internist, Research Institute of Medical Climatology and Rehabilitation Therapy, Vladivostok Branch of Far Eastern Scientific Center for Physiology and Pathology of Respiration, Russian Academy of Medical Sciences, Vladivostok, Russia. https://orcid.org/0000-0003-0396-6380.

Tatyana A. Gvozdenko - MD, PhD, Principal Research Scientist, Laboratory of Rehabilitation Therapy, Research Institute of Medical Climatology and Rehabilitation Therapy, Vladivostok Branch of Far Eastern Scientific Center for Physiology and Pathology of Respiration, Russian Academy of Medical Sciences, Vladivostok, Russia. https://orcid.org/0000-0002-6413-9840.

Oksana Yu. Kytikova - MD, PhD, Research Scientist, Laboratory of Rehabilitation Therapy, Research Institute of Medical Climatology and Rehabilitation Therapy, Vladivostok Branch of Far Eastern Scientific Center for Physiology and Pathology of Respiration, Russian Academy of Medical Sciences, Vladivostok, Russia. https://orcid.org/0000-0001-5018-0271. 